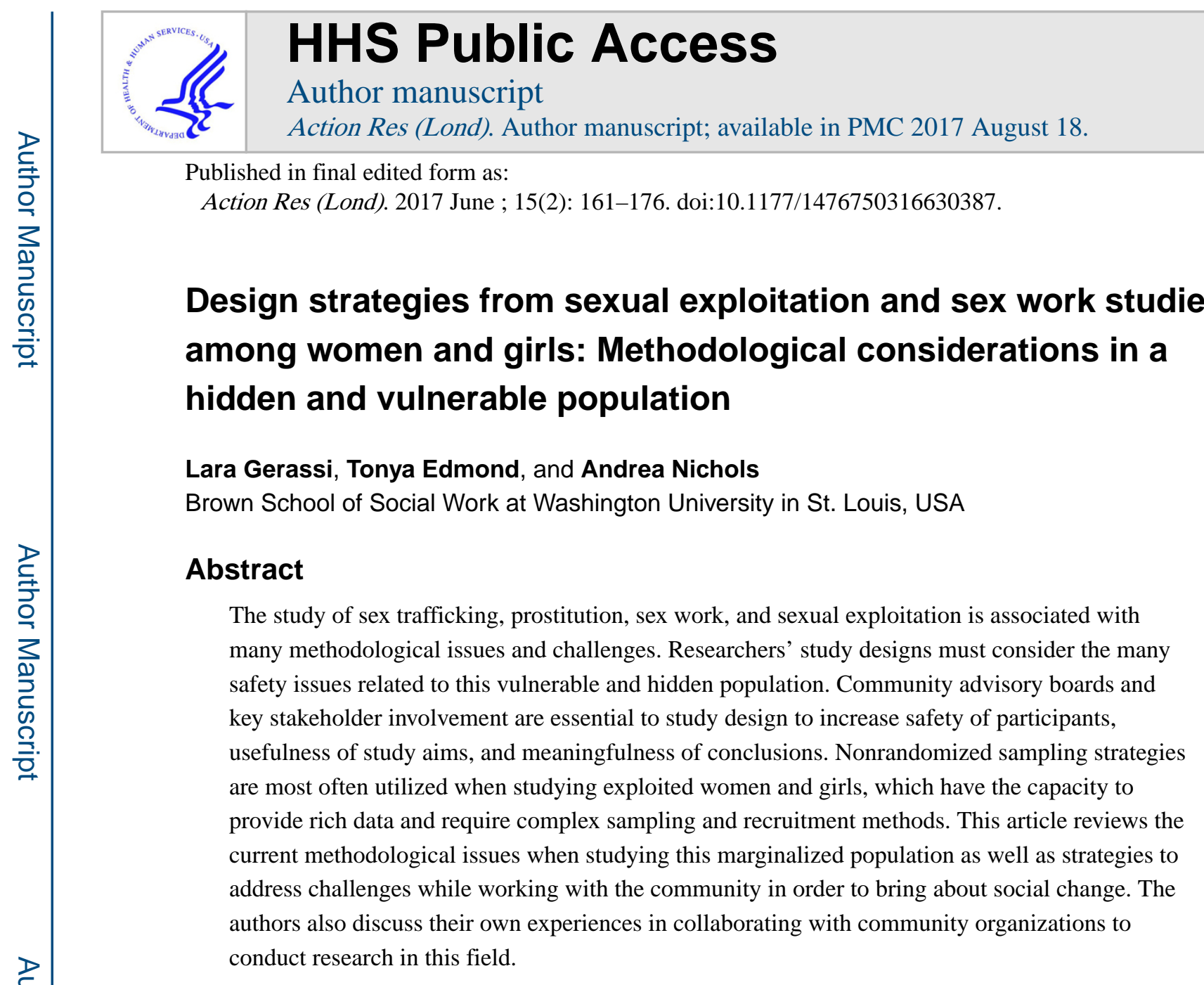

Keywords

Measurement; study design; sampling strategies; sexual exploitation; sex trafficking; females

\title{
Introduction
}

There are numerous methodological issues to consider when studying individuals who trade or sell sex, some of whom may be described or self-identify as victims, prostitutes, or sex workers and traders. The complexity of definitions related to individuals who trade or sell sex in some capacity is described elsewhere in great detail (Gerassi, 2015). The ways in which we describe individuals who trade or sell sex (i.e. prostitutes, trafficked individuals, sex workers, etc.) often create challenges in study design and measurement of the scope of the problem. Ranging degrees of force and coercion involved in sexual exploitation as well as differences in terminology require clear inclusion criteria that will further advance the field of study in this area. Consequently, the discussion here will draw primarily from

Reprints and permissions: sagepub.co.uk/journalsPermissions.nav

Corresponding author: Lara Gerassi, Brown School of Social Work at Washington University in St. Louis, One Brookings Drive, St. Louis, MO 63130, USA. 1gerassi@wustl.edu.

Declaration of Conflicting Interests

The author(s) declared no potential conflicts of interest with respect to the research, authorship, and/or publication of this article. 
existing literature to explore best practices when designing studies that focus broadly on the study of individuals who are exploited in some way into trading or selling sex.

Designing studies in collaboration with community partners and other experts from the field is an important step to ensure the safety of participants in addition to high levels of participant recruitment and overall success of the project. It is important to consider participants' safety, particularly among hidden and hard-to-reach populations, while also maintaining high methodological rigor and utilizing various sampling strategies to be as inclusive as possible of the wide ranging experiences survivors may have. Although community involvement and collaboration may be time consuming to any research agenda, it is essential to the feasibility and utility of the research process and results. In addition to review of existing best practices, the first and third author have conducted qualitative research with anti-sex trafficking/exploitation coalitions and community organizations. Research questions and applicability were strengthened by collaboration and existing participation with community boards and coalition members. Existing partnerships were critical in crafting research questions and dissemination of findings. The rest of of the sampling strategies that target sexually exploited women are a review of the literature.

This article reviews the methodological developments and sampling techniques when studying sexual exploitation and sex work drawing from the extant research, and closes with a reflexive account of the benefit of community collaboration in study design.

\section{Methodological considerations}

The process of designing a safe and highly rigorous study of sexually exploited women and girls is not without its challenges. There are many dimensions to consider with regard to participants' emotional and physical safety as well as the ethics of recruiting an exploited population for the purposes of research. Due to the hidden nature of the population, nonrandomized sampling techniques must are often utilized, charging researchers to balance methodological rigor and feasibility. Community and key stakeholder involvement will increase the likelihood of gathering rich data, drawing meaningful conclusions, and creating the most impact from the study. Project designs and sampling strategies have become more diverse and stronger methodologically, especially in the use of innovative recruitment techniques. The following section reviews the major methodological issues when conducting research with sexually exploited women and girls.

\section{Participant safety}

It is imperative to employ strategies to increase safety measures for both participants and researchers, particularly when studying highly stigmatized and vulnerable populations involved in dangerous situations. Guided by 10 basic principles of conduct, the World Health Organization released ethical and safety recommendations for interviewing trafficked women (Zimmerman \& Watts, 2003). In addition to ethical requirements of any research interviewer (i.e. obtaining informed consent), particular emphasis is placed on assessing the associated risks and possibility of retraumatization before undergoing the interview with each participant. With a population that is known to experience high levels of abuse and exploitation, risk of retraumatization remains high (Cwikel \& Hoban, 2005). In addition to 
sensitivity throughout the interview, it is essential for an interviewer to be able to provide referral information for any services she may request and/or indicate needing as well as be prepared for emergency situations should they arise (i.e. a participant discloses that she is in immediate danger and safety planning is required).

Even the process of disclosing one's name or having to call for an appointment and return at another time may be challenging for this population. To address this challenge, Martin, Hearst, and Widome (2010) utilized recruitment flyers throughout a particular target neighborhood that, in addition to describing sample criteria, indicated that "all information is confidential and anonymous-we do not ask your name" (p. 10). Individuals were encouraged to take tear-off portions of the flyer with the researchers' first names and phone numbers only and were never required to provide names or identifying information over the phone or in the interviews. These described precautions were taken to increase the safety of participants and researchers throughout the course of the study.

\section{Study design}

Beyond the essential safety considerations, designing studies in order to effectively and rigorously survey and understand this population without causing further exploitation or harm is both critical and challenging. Participatory research models in which researchers' partner with community-based organizations as well as members of the target population when possible have become increasingly utilized (Tiffany, 2006; Urada \& Simmons, 2014). Ongoing involvement in organized groups may also be helpful in processing complex problems in practice and research. For example, our ongoing involvement in a local coalition, which includes survivors of and practitioners who address sexual exploitation has been essential in shaping research questions and in gaining support for ongoing projects. Without this ongoing participation and collaboration, our insight into the challenges of serving this complex population would be hindered. These partnerships and trusted relationships are important in the design of any study involving sexually exploited women and girls.

Participatory research methods-Participatory research aims to combine investigation, education, and action while taking measures to involve the participation of "oppressed and ordinary people in the problem posing and solving" (Maguire, 2008, pp. 417-418). As such, this educational process for both researchers and participants analyzes the named problem and takes collective action as a planned consequence of scientific inquiry. While models of participatory research may vary, there are five general guidelines to be upheld with any project (Maguire, 2008): (1) organization of the project and knowledge of the working area, which requires establishing relationships with community organizations, leaders, institutions, and therefore originates within the particular community; (2) process by which researchers and participants identify and understand various perceptions of the most significant problem within the community; (3) advancing inquiry in which researchers and participants compile questions and themes to be investigated; (4) researching social reality and analyzing collected information in which the research is designed and conducted by researchers with community partners; and (5) definition of action projects, in which researchers and community members decide on next steps to address the identified problem. 
Involving community practitioners as well as members of the target population (who are in a safe and emotionally ready space to participate healthily) can be essential to the safety and breadth of any project with this population. In addition, working closely with practitioners may also increase both the dissemination of research findings and community buy-in of resulting recommendations (Urada \& Simmons, 2014).

One step in involving community participation is the creation of a community advisory panel or board, which may provide much needed perspective to translate methodological designs into reality and strengthen safety measures taken against coercion of participants (Martin et al., 2010; Miller et al., 2011; Shaver, 2005). Community advisory boards can be assembled through coalitions or other advocates working with the population of interest as well as members of that population, as applicable. For example, in its original design Martin (2013) relied on study participants to come into contact with probation, law enforcement, prostitution-specific programming or other locales, and subsequently be recruited into the study by those partners. Participants were asked to call and schedule an appointment, yielding 20 calls from participants and only four completed interviews. Based on feedback from the committee, consisting of practitioners and individuals who traded sex, the project shifted its approach from an appointment-based design to a completely anonymous, drop-in model utilizing outreach flyers that neither required nor even asked names or any identification (as previously described). Researchers credit their collaboration with community practitioners and individuals who had previously traded sex with the restructuring and ultimate success with the project.

Community advisory boards may also be quite helpful in the operationalization and design of quantitative studies of trading sex/sexual exploitative behaviors, as studies have handled count variables in a variety of ways and can present limitations to the research findings. Some studies establish individual count variables to provide descriptive information of trading/selling sex behavior, such as one study which asked its participants, "have you been paid by someone for having a sexual relationship with them?" (Reid \& Piquero, 2014, p. 250). Another study utilized a single dichotomous variable $(0=$ no personal exposure to sex trade, $1=$ any personal exposure to sex trade), in which respondents were determined to have been exposed to the sex trade if they said yes to any question regarding receiving money by having sex with someone, exchanging sex for money, gifts, drugs, or a place to stay (Kennedy, Bybee, Kulkarni, \& Archer, 2012).

Other examples include several count variables that are then added into an overall sexual risk behavior score. For example, one study assessed HIV/AIDs risk behavior by totaling the score of 11 questions with dichotomous answers that included variables of having sexual intercourse under the influence of drug/alcohol, exchanging sex, etc. (Chen \& Biswas, 2011). While this may have served the study's purpose to examine HIV/AIDS risk generally, this method can be problematic as it does not decipher differences between having sex under the influence and trading sex, thus grouping together all forms of risky behavior that may not be comparable. Count variables in quantitative research risk losing the voice of the individuals' experiences as to what led to these forms of behaviors; however, community advisory boards should have experiences as to what these different types of sexual/high risk encounters may look like, providing much needed context to inform study design. 
Partnering with the community would reduce limitations of count variables and existing scales, creating the potential to provide richer data. Empirical studies that utilize quantitative and qualitative methodological designs and are grounded in partnership with stakeholders have the opportunity to construct more meaningful research questions that are applicable to sexually exploited populations. Without such partnerships, researchers remain at risk of conducting poor and meaningless social science. Research questions and subsequent findings may not elucidate the true nature of sexual exploitation and may lead to counterproductive decisions with regard to identification, prevention, and practice. Utilizing a community advisory board or other forms of member checking throughout the methodological process may strengthen the quality of the project and the utility and applicability of the results. Consequently, it is important to look for details describing such community advisory boards or community involvement throughout research publications and reports. Such information gives us context as to whether the study design choices made attempted to consider all practical implications to collecting data safely and the dissemination and implementation of results among local communities.

\section{Sampling methodology and recruitment strategies with hidden populations}

Nonrandomized sampling strategies with increasing rigor and innovative methodology are almost always utilized with the study of hidden and hard-to-reach populations, such as sexually exploited individuals. The majority of studies focusing on sexual exploitation and sex work have utilized a qualitative approach, which requires nonrandomized sampling strategies, as these studies generally aim to uncover phenomena and understand processes that would be lost in quantitative designs (Padgett, 2008). Such applications of rigor will strengthen the study's results and ability to draw meaningful conclusions. Purposive sampling (snowball sampling in particular) and facility-based (or target) sampling are most often utilized for hidden, stigmatized populations and can present various strengths and weaknesses for methodological rigor. Despite some criticism, a relatively new technique in the literature called respondent-driven sampling (RDS) is gaining increased evidence as another rigorous sampling strategy for hidden populations and has primarily been used to administer surveys and collect data. The diversification of sampling strategies has also been shown to provide a more inclusive sample of any heterogeneous target population (Singer, 2013). This section reviews the relevant sampling strategies and the state of rigor associated with each method as well as recruitment techniques for hidden and hard-to-reach populations.

Purposive sampling-Purposive sampling is commonly used with the study of sexual exploitation and sex work, particularly when a qualitative study is designed. Purposive sampling is defined as the "deliberate process of selecting respondents based on their ability to provide the needed information" (Padgett, 2008, p. 53) and is often used to examine a particular phenomenon that is rare or hidden from general view. Snowball sampling, a particular type of purposive sampling, involves a subgroup of the population of interest helping to identify other subgroup members through referral (Magnani, Sabin, Saidel, \& Heckathorn, 2005). The first respondents to the study, known as seeds, then refer other individuals who meet inclusion criteria to researchers. A review of the evidence suggests that snowball sampling is the most commonly utilized method for studying sexually 
exploited women and girls, as it is described in multiple studies (i.e. Campbell, Ahrens, \& Clark, 2003; Cusick, Brooks-Gordon, Campbell, \& Edgar, 2011; Cusick \& Hickman, 2005; Dodsworth, 2014; Koken, 2011; Kurtz, Surratt, Inciardi, \& Kiley, 2004; Kurtz, Surratt, Kiley, \& Inciardi, 2005; Lucas, 2005; Nichols, 2012; Oselin, 2010; Raphael, Reichert, \& Powers, 2010; Reichert \& Sylwestrak, 2013; Sanders, 2007; Williamson \& Folaron, 2003; Wilson \& Dalton, 2008).

Although purposive (and specifically snowball) sampling allows for stigmatized or hidden populations to be interviewed or surveyed, it has been criticized for its tendency to sample more cooperative participants as well as those already connected to a particular service. Thus, the truly stigmatized or hidden members of that population who may have fewer or no known connections to the original seeds may be missed (Shaver, 2005). This further underscores the importance of community involvement and collaboration when designing the study, as they may be able to penetrate into more hidden networks than the researcher could do alone. This method may be essential in shedding light on a particular phenomenon for a subpopulation, such as women involved in street-based prostitution in the Midwest (Williamson \& Baker, 2009) or understanding advocates' utilization of survivor-defined practices in the protective order process (Nichols, 2012). When conducting qualitative work, findings should lead to saturation, that is a point in which the collection of new data does not shed any further light on the issue under investigation (Mason, 2010). Because qualitative work aims to uncover contextual complexities and key dynamics of a particular phenomenon and not necessarily generalize to an entire population, nonrepresentative sampling (and particularly purposive sampling) is considered a rigorous and appropriate methodology (Padgett, 2008).

Facility-based sampling-Facility-based or target sampling involving one particular location is often used to capture experiences, correlates, and prevalence of sexually exploited women and girls in prisons or juvenile detention (Lopez et al., 2011; Millay, Satyanarayana, O'Leary, Crecelius, \& Cottler, 2009; Otto-Salaj, Gore-Felton, McGarvey, \& Canterbury, 2002; Raj et al., 2006; Voisin, Hong, \& King, 2012), prostitution diversion or exiting programs (Clarke, Clarke, Roe-Sepowitz, \& Fey, 2012; Leon \& Shdaimah, 2012; RoeSepowitz, Hickle, \& Cimino, 2012; Shdaimah \& Wiechelt, 2012), or community-based treatment programs (Carroll \& Trull, 2001; Surratt \& Inciardi, 2004; Twill, Green, \& Traylor, 2010; Van Leeuwen et al., 2004). In addition, many government reports cite prevalence statistics from hotline call centers, which requires individuals to self-identify or identify another as a potential sex trafficking victim in order to file a report (Lange, 2010). Facility-based sampling is particularly helpful in understanding the dynamics of those individuals who actually seek services voluntarily or are mandated through law enforcement (Magnani et al., 2005; Martin, 2013). Although it can be useful if the researcher is able to penetrate all networks of the population, it may also result in the overrepresentation of the more visible participants (i.e. street workers as compared to those who trade sex inside; Oselin, 2014; Shaver, 2005). Clinical samples are limited, in that those who receive services may have distinct experiences from those who do not access them or who choose not to use them. 
RDS—RDS, a participatory and community-based sampling approach, is now being utilized in studies of people who trade or sell sex both alone or in combination with other sampling strategies (Curtis, Terry, \& Dank, 2008; Lutnick \& Cohan, 2009; Marcus et al., 2011). Based on the premise that peers are better able to recruit other members of a hidden population than researchers or even outreach workers, this method involves chain-referral (or snowball) sampling techniques while monitoring and recording participants' networks (Abdul-Quader, Heckathorn, Sabin, \& Saidel, 2006; Tiffany, 2006). RDS begins with a small number of individuals, known as seeds, and expands participant involvement through various waves of peer recruitment. After participating, the original seeds are given "coupons" or some other form of documentation and asked to give coupons to a fixed number of peers within the sampling frame. When the second wave of participants are recruited and interviewed, they are then given the same predetermined number of coupons to give their peers until several waves of recruitment have occurred. In order for this method to be employed as it was intended, Magnani et al. (2005) state that RDS requires four essential components: (1) documentation of who recruited whom must be tracked, generally through a coupon system; (2) recruitment must be rationed with generally no more than three coupons per "seed" (so as not to over sample from one particular network and to obtain a variety of different perspectives); (3) information on personal network size must be gathered and recorded; and (4) recruiters and recruits must know one another in some way. Without the presence of just one of these components, true RDS has not occurred.

RDS is helpful in creating voice as it requires considerable interactions with key stakeholders, and thus can give a voice to research in a way that other traditional quantitative methods may not. Like all sampling strategies, there is a potential for biases primarily in the convenience sample of the original sample seeds and preferential referral by respondents leading to bias (Gile \& Handcock, 2010). Additionally, "seeds" will most likely distribute their coupons to individuals with whom they have better relationships but who may not necessarily best meet specified inclusion criteria. For example, a participant of a study targeting exploited individuals only may give a coupon to a friend who does not identify as exploited. To combat these potential problems, Gile and Handcock (2010) recommend that researchers pay particular attention in the selection of initial seeds in ensuring that they meet specified inclusion criteria of the target population and across various population components. In addition, targeting individuals with a broader terminology (i.e. trading sex as compared to prostitutes or victims) may be more helpful. This process can and we hope would occur with community involvement to strengthen the feasibility and utility of the study. However, this method may not be the best fit for all studies within this population, as it requires seeds or participants to provide some identifying information (such as a name) to be tracked in some way and therefore creates potential challenges for safety. Those with safety or confidentiality concerns may consequently be less likely to participate, thereby limiting the sample. With the involvement and collaboration of a community board, the most rigorous yet safest study design may be achieved. Additionally, several studies have shown evidence of the effectiveness of this strategy in accessing hidden and stigmatized populations' networks and therefore obtain a fuller picture of the population, particularly in urban environments (Abdul-Quader, Heckathorn, McKnight, et al., 2006; Johnston, Sabin, Mai, \& Pham, 2006). 
Outreach recruitment-Outreach methods of recruitment are seen as a bridge between service providers and those in need of services and may be a tool of selective recruitment from designated zones or neighborhoods by specific subgroups (Singer, 2013). In using this method for research purposes, there are three criteria for evaluation of potential use and rigor, which include (1) ability to reach the target population, (2) ability to successfully rerecruit appropriate study participants, and (3) ability to rerecruit participants for follow-up as necessary (Singer, 2013). Effective outreach techniques (in both research and practice) depend on the development of rapport, trust in relationships, and nonjudgmental attitudes (Connolly \& Joly, 2012; Holger-Ambrose, Langmade, Edinburgh, \& Saewyc, 2013). Outreach recruitment methods within particular geographic areas and in conjunction with outreach organizations that are already integrated into target communities may be instrumental in accessing a hidden population, as this population subgroup may not come into contact with services any other way.

Researchers who have conducted this work appear to have different philosophies on the implementation of outreach methods in the field. For example, Shaver (2005) strolled in known areas of prostitution, introduced themselves and their research projects, and provided potential participants with business cards with full research center and other contact information. Others have opted out of this type of procedure in the event that identifying information was found by another party (i.e. such as a pimp; Martin, 2013). These differences in methodological designs may perhaps underscore the need for community involvement and/or community advisory groups to provide insight into safety and other considerations within the particular research contexts.

Mobile van and field station approaches-While confidentiality and anonymity are key concepts in any research study, these concerns are of particular importance to women and girls who live in potentially dangerous and even lethal situations. There are different strategies to increase safety while targeting hard-to-reach and hidden populations, such as sexually exploited women and girls. The utilization of a mobile van or stationary field site has gained support as a technique to both increase safety and conduct a methodologically rigorous study (Singer, 2013). Utilizing a van or a field station allows researchers and outreach workers to have a safe space where they can conduct interviews in addition to keeping incentives, safe sex kits, referral literature, and manuals that outreach workers and researchers would normally have to carry with them (Janssen, Gibson, Bowen, Spittal, \& Petersen, 2009). Partnerships in place with a fixed field site has the potential to increase general access to services, as participants of the research study may return to the same sites to acquire prevention materials, snacks, or safe sex kits. In this case, the field center could cater to participants' needs as they are uncovered and thus serve as a full or partial link to services.

Diversification of sampling and recruitment strategies-One way to ensure increased variability of experiences when studying hidden and hard-to-reach populations is to diversify sources and strategies of recruitment. According to Singer's chapter on sampling methodology with hidden and hard-to-reach populations (2013), studies have accomplished variability by recruiting from multiple sources such as a study of injection drug users where 
participants were recruited through a corrections facility, county health clinics, private welfare organizations and street outreach, or another study in Baltimore that added sexually transmitted disease clinics and emergency rooms. Another approach would be to begin with purposive sampling and continue with participant-led recruitment strategies from fixed sites. The diversification of sampling strategies and sites (i.e. multiple organizations) has the potential to increase the methodological rigor of any project while capturing multiple voices and experiences to sufficiently address research aims.

\section{Reflexive analysis: Collaboration with community organizations in study design}

Particularly in exploring hard-to-reach or little examined populations, involvement with community organizations and/or coalitions can be useful in developing research questions, establishing trust, and gaining access to or expanding samples. For example, in a study examining domestic violence victim advocacy practices conducted by the third author, relationships with individuals in two participating organizations had already been established through volunteer work, as well as personal and professional relationships (Nichols, 2012, 2013, 2014). Through these relationships, informal discussions of challenges to advocacy and key research needs took place over a period of time, eventually guiding the study design and resulting research questions. At the point of beginning the research project, initial respondents were eager and willing to participate, and allowed use of their names in developing further contacts. No invitation to participate was declined, and each subsequent interviewee made additional referrals, also allowing the use of their names upon recruitment of further research participants. Ostensibly, collaboration with community organizations allowed for entrée and an expanded sample, and opened doors to examining victim advocacy in varied organizational contexts. Further, as the initial contacts were generally respected in the field, this facilitated trust and rapport building, and the resulting data were rich with disclosure of both benefits and challenges associated with collaboration with the criminal justice system, in what may have otherwise been a sensitive and guarded area of disclosure. Moreover, member-checking techniques were easily utilized, offering additional insights into the interpretation of the data.

More recently, the first and third authors engaged in a research project examining dynamics in sex trafficking/ CSE coalitions, including benefits, challenges, tensions, and suggestions for further action (Gerassi \& Nichols, 2016). The first author had long-established relationships with two of the coalitions, regularly participating in community meetings and decision making, and remained engaged as a practitioner and research scholar. The third author had long-standing intermittent involvement with one of the coalitions and had engaged in a research project two years prior involving coalition members. Similar to the example described above, coalition involvement led to the development of the research questions, access to a sampling frame of those working in varied organizational contexts, ease in gaining sample participants, and trust building resulting in richly detailed data. Because of coalition involvement, existing tensions and challenges were already known. Discussion of tensions and challenges among the first and third author, as well as with multiple coalition members over a number of years, resulted in the development of the 
research questions. Between both researchers, established relationships with coalition members allowed for the development of trust and rapport, and resulted in disclosure of sensitive material, including hotly contested perspectives, clashing ideologies, and challenging experiences. With one exception, coalition members unreservedly expressed benefits and challenges associated with coalition membership and related action. Importantly, coalition involvement also resulted in coalition members' interest in disseminating the research findings with an emphasis on further action to improve coalition activities. Members expressed a high level of interest in "results," with the aim of making improvements in coalition and community collaboration. This led to the development of a session to disseminate and discuss the research findings and next steps. Member-checking techniques have been long established in qualitative research, offering the benefit of further discussion and addressing any discrepancies or misinterpretations of the data. The authors found member-checking techniques were also useful in maintaining interest and providing utility in the results of the action-oriented research.

\section{Conclusion}

This article has underscored the importance of designing studies that lend themselves to rigorous research techniques as well as ethical considerations that must be emphasized with regard to participant and researcher safety. Researchers are charged with understanding as much about the community as possible from both literature and experts working with individuals on the ground, particularly when studying hidden and vulnerable populations such as sexually exploited women and girls. The plethora of challenges in studying this population coupled with various definitional differences in terminology (Gerassi, 2015) in this field have shaped the state of the literature in this area. It is our hope that this piece will add to a body of work aimed to strengthen researchers' community collaborations and methodological approaches when designing projects in this important area of study.

\section{Acknowledgements}

I as corresponding author affirm that I have listed everyone who contributed significantly to this work. We would like to thank Dr. Davydd Greenwood, for leading the review process of this article. Should there be any comments/ reactions you wish to share, please bring them to the interactive portion (Reader Responses column) of the website: http://arj.sagepub.com.

\section{Funding}

The author(s) disclosed receipt of the following financial support for the research, authorship, and/or publication of this article: Ms. Gerassi is supported by a TranSTAR T32 Predoctoral Fellowship (DA015035). No other financial support was received for the research, authorship, and/or publication of this article.

\section{Author biographies}

Lara Gerassi is a TranSTAR T32 (NIDA) Predoctoral Fellow at the Brown School of Social Work at Washington University in St. Louis. She is a student affiliate of the Center for Violence \& Injury Prevention. After receiving her MSW, she practiced for several years and earned her LCSW before returning for doctoral studies. Her research interests focus on sex trafficking and commercial sexual exploitation with particular emphasis on communitybased responses to survivors. 
Tonya Edmond is the Associate Dean for Diversity and an Associate Professor at the School of Social Work at Washington University in St. Louis where she is a faculty affiliate of the Center for Violence \& Injury Prevention. Her research focuses on testing the effectiveness of interventions for survivors of childhood sexual abuse, sexual assault, and domestic violence and the implementation of evidence based trauma treatments in community based nonprofit agencies. She completed her Ph.D. at the University of Texas at Austin.

Andrea Nichols is a Professor of Sociology at Forest Park College and Lecturer for the Women, Gender and Sexuality Studies Dept. and Brown School of Social Work at Washington University in St. Louis. She received her Ph.D. in Criminology from the University of Missouri St. Louis in 2011. Her practitioner-focused research and teaching interests center upon advocacy in the contexts of sex trafficking/commercial sexual exploitation and intimate partner violence.

\section{References}

Abdul-Quader AS, Heckathorn DD, McKnight C, Bramson H, Nemeth C, Sabin K, Des Jarlais DC. Effectiveness of respondent-driven sampling for recruiting drug users in New York City: Findings from a pilot study. Journal of Urban Health. 2006; 83(3):459-476. doi:10.1007/s11524-006-9052-7. [PubMed: 16739048]

Abdul-Quader AS, Heckathorn DD, Sabin K, Saidel T. Implementation and analysis of respondent driven sampling: Lessons learned from the field. Journal of Urban Health. 2006; 83(7):1-5. doi: 10.1007/s11524-006-9108-8. [PubMed: 16736349]

Campbell R, Ahrens CE, Clark ML. Adult sexual assault and prostitution: An exploratory analysis. Violence and Victims. 2003; 18(3):299-317. [PubMed: 12968660]

Carroll JJ, Trull LA. Drug-dependent homeless African-American women's perspectives of life on the streets. Journal of Ethnicity in Substance Abuse. 2001; 1(1):27-45. doi:10.1300/J233v01n01_03.

Chen S, Biswas B. Behavioural correlates of dual diagnosis among women in treatment for substance abuse. Mental Health and Substance Use. 2011; 5:217-227. doi:10.1080/17523281.2011.631933.

Clarke RJ, Clarke EA, Roe-Sepowitz D, Fey R. Age at entry into prostitution: Relationship to drug use, race, suicide, education level, childhood abuse, and family experiences. Journal of Human Behavior in the Social Environment. 2012; 22(3):270-289. doi:10.1080/10911359.2012.655583.

Connolly JA, Joly LE. Outreach with street-involved youth: a quantitative and qualitative review of the literature. Clinical Psychology Review. 2012; 32(6):524-534. doi:10.1016/j.cpr.2012.05.006. [PubMed: 22728669]

Curtis, R., Terry, K., Dank, M. The commercial sexual exploitation of children in New York City Volume One The CSEC Population in New York City: Size, Characteristics. Center for Court Innovation. 2008. Retrieved from https://www.ncjrs.gov/pdffiles1/nij/grants/225083.pdf

Cusick L, Brooks-Gordon B, Campbell R, Edgar F. "Exiting" drug use and sex work: Career paths, interventions and government strategy targets. Drugs: Education, Prevention, and Policy. 2011; 18(2):145-156. doi:10.3109/09687631003776901.

Cusick L, Hickman M. "Trapping” in drug use and sex work careers. Drugs: Education, Prevention, and Policy. 2005; 12(5):369-379. doi:10.1080/09687630500226779.

Cwikel J, Hoban E. Contentious issues in research on trafficked women working in the sex industry: Study design, ethics, and methodology. Journal of Sex Research. 2005; 42(4):306-316. doi: 10.1080/00224490509552286. [PubMed: 19827235]

Dodsworth J. Sexual exploitation, selling and swapping sex: victimhood and agency. Child Abuse Review. 2014; 23:185-199. February 2013. doi:10.1002/car. 
Gerassi L. From exploitation to industry: Definitions, risks, and consequences of domestic sexual exploitation and sex work among women and girls. Journal of Human Behavior in the Social Environment. 2015; 25(6):591-605. [PubMed: 26726289]

Gerassi, L., Nichols, A. Coalition heterogeneity in community-based responses to sex trafficking and commercial sex; Society for Social Work and Research 20th Annual Conference: Grand Challenges of the American Academy of Social Work and Social Welfare Initiative; Sswr. 2016, January;

Gile K, Handcock MS. Respondent-driven sampling: An assessment of current methodology. Sociology Methodology. 2010; 40(1):1-34. doi:10.1111/j.1467-9531.2010.01223.x.RespondentDriven.

Holger-Ambrose B, Langmade C, Edinburgh LD, Saewyc E. The illusions and juxtapositions of commercial sexual exploitation among youth: Identifying effective street-outreach strategies. Journal of Child Sexual Abuse. 2013; 22(3):326-340. doi:10.1080/10538712.2013.737443. [PubMed: 23590353]

Janssen PA, Gibson K, Bowen R, Spittal PM, Petersen KL. Peer support using a mobile access van promotes safety and harm reduction strategies among sex trade workers in Vancouver's downtown eastside. Journal of Urban Health. 2009; 86(5):804-809. doi:10.1007/s11524-009-9376-1. [PubMed: 19533367]

Johnston LG, Sabin K, Mai TH, Pham TH. Assessment of respondent driven sampling for recruiting female sex workers in two Vietnamese cities: reaching the unseen sex worker. Journal of Urban Health?: Bulletin of the New York Academy of Medicine. 2006; 83(6 Suppl):i16-28. doi:10.1007/ s11524-006-9099-5. [PubMed: 17031567]

Kennedy AC, Bybee D, Kulkarni SJ, Archer G. Sexual victimization and family violence among urban African American adolescent women: Do violence cluster profiles predict partner violence victimization and sex trade exposure? Violence Against Women. 2012; 18:1319-1338. doi: 10.1177/1077801212470544. [PubMed: 23334817]

Koken JA. Independent female escort's strategies for coping with sex work related stigma. Sexuality and Culture. 2011; 16(3):209-229. doi:10.1007/s12119-011-9120-3.

Kurtz SP, Surratt HL, Inciardi JA, Kiley MC. Sex work and “date” violence. Violence Against Women. 2004; 10(4):357-385. doi:10.1177/1077801204263199.

Kurtz SP, Surratt HL, Kiley MC, Inciardi JA. Barriers to health and social services for street-based sex workers. Journal of Health Care for the Poor and Underserved. 2005; 16(2):345-361. doi:10.1353/ hpu.2005.0038. [PubMed: 15937397]

Lange A. Research note: Challenges of identifying female human trafficking victims using a national 1-800 call center. Trends in Organized Crime. 2010; 14(1):47-55. doi:10.1007/ s12117-010-9107-8.

Leon CS, Shdaimah CS. JUSTifying scrutiny: State power in prostitution diversion programs. Journal of Poverty. 2012; 16(3):250-273. doi:10.1080/10875549.2012.695539.

Lopez V, Kopak A, Robillard A, Gillmore MR, Holliday RC, Braithwaite RL. Pathways to sexual risk taking among female adolescent detainees. Journal of Youth and Adolescence. 2011; 40(8):945957. doi:10.1007/s10964-010-9623-5. [PubMed: 21188488]

Lucas AM. The work of sex work: Elite prostitutes' vocational orientations and experiences. Deviant Behavior. 2005; 26(6):513-546. doi:10.1080/01639620500218252.

Lutnick A, Cohan D. Criminalization, legalization or decriminalization of sex work: What female sex workers say in San Francisco, USA. Reproductive Health Matters. 2009; 17(34):38-46. [PubMed: 19962636]

Magnani R, Sabin K, Saidel T, Heckathorn D. Review of sampling hard-to-reach and hidden populations for HIV surveillance. AIDS. 2005; 19(Supplement 2):S67-S72. doi:10.1097/01.aids. 0000172879.20628.e1.

Maguire, P. Feminist participatory research framework. In: Jaggar, AM., editor. Just Methods: An Interdisciplinary Feminist Reader. Paradigm; Boulder, CO: 2008.

Marcus A, Riggs R, Horning A, Rivera S, Curtis R, Thompson E. Is child to adult as victim is to criminal? Sexuality Research and Social Policy. 2011; 9(2):153-166. doi:10.1007/ s13178-011-0070-1. 
Martin L. Sampling and sex trading: Lessons on research design from the street. Action Research. 2013; 11(3):220-235. doi:10.1177/1476750313488146.

Martin L, Hearst MO, Widome R. Meaningful differences: Comparison of adult women who first traded sex as a juvenile versus as an adult. Violence Against Women. 2010; 16(11):1252-1269. doi:10.1177/1077801210386771. [PubMed: 21097962]

Mason M. Sample size and saturation in $\mathrm{PhD}$ studies using qualitative interviews. Qualitative Social Research. 2010; 11(3):1-19.

Millay TA, Satyanarayana VA, O’Leary CC, Crecelius R, Cottler LB. Risky business: Focus-group analysis of sexual behaviors, drug use and victimization among incarcerated women in St. Louis. Journal of Urban Health: Bulletin of the New York Academy of Medicine. 2009; 86(5):810-817. doi:10.1007/s11524-009-9381-4. [PubMed: 19533363]

Miller CL, Fielden SJ, Tyndall MW, Zhang R, Gibson K, Shannon K. Individual and structural vulnerability among female youth who exchange sex for survival. The Journal of Adolescent Health. 2011; 49(1):36-41. doi:10.1016/j.jadohealth.2010.10.003. [PubMed: 21700154]

Nichols AJ. Survivor-defined practices to mitigate revictimization of battered women in the protective order process. Journal of Interpersonal Violence. 2012; 28(7):1403-1423. doi: 10.1177/0886260512468243. [PubMed: 23262828]

Nichols AJ. Meaning-making and domestic violence victim advocacy: An examination of feminist identities, ideologies, and practices. Feminist Criminology. 2013; 8(3):177-201. doi: $10.1177 / 1557085113482727$.

Nichols AJ. No-drop prosecution in domestic violence cases: Survivor-defined and social change practices. Journal of Interpersonal Violence. 2014; 29(11):2114-2142. doi: 10.1177/0886260513516385. [PubMed: 24390358]

Oselin SS. Weighing the consequences of a deviant career: Factors leading to an exit from prostitution. Sociological Perspectives. 2010; 53(4):527-550. doi:10.1525/sop.2010.53.4.527.SOP5304.

Oselin, SS. Leaving Prostitution: Getting out and Staying out of Sex Work. New York University Press; New York: 2014.

Otto-Salaj LL, Gore-Felton C, McGarvey E, Canterbury RJ. Psychiatric functioning and substance use: Factors associated with HIV risk among incarcerated adolescents. Child Psychiatry and Human Development. 2002; 33(2):91-106. Retrieved from http://www.ncbi.nlm.nih.gov/pubmed/ 12462349. [PubMed: 12462349]

Padgett, D. Qualitative Methods in Social Work Research. 2nd ed.. Sage Publications; Thousand Oaks, CA: 2008.

Raj A, Clarke JG, Silverman JG, Rose J, Rosengard C, Hebert M, Stein M. Violence against women associated with arrests for sex trade but not drug charges. International Journal of Law and Psychiatry. 2006; 29(3):204-211. doi:10.1016/j.ijlp.2005.09.004. [PubMed: 16563506]

Raphael J, Reichert JA, Powers M. Pimp control and violence: Domestic sex trafficking of Chicago women and girls. Women and Criminal Justice. 2010; 20(1-2):89-104. doi: 10.1080/08974451003641065.

Reichert, J., Sylwestrak, A. National survey of residential programs for victims of sex trafficking: National survey of residential programs for victims of sex trafficking. The Illinois Criminal Justice Information Authority; Chicago, IL: 2013.

Reid JA, Piquero AR. On the relationships between commercial sexual exploitation/prostitution, substance dependency, and delinquency in youthful offenders. Child Maltreatment and Emerging Adulthood: Clinical Populations. 2014; 19(3-4):247-260. doi:10.1177/1077559514539752.

Roe-Sepowitz DE, Hickle KE, Cimino A. The impact of abuse history and trauma symptoms on successful completion of a prostitution-exiting program. Journal of Human Behavior in the Social Environment. 2012; 22(1):65-77. doi:10.1080/10911359.2011.598830.

Sanders T. Becoming an ex-sex worker: Making transitions out of a deviant career. Feminist Criminology. 2007; 2(1):74-95. doi:10.1177/1557085106294845.

Shaver FM. Sex work research: methodological and ethical challenges. Journal of Interpersonal Violence. 2005; 20(3):296-319. doi:10.1177/0886260504274340. [PubMed: 15684139] 
Shdaimah CS, Wiechelt SA. Converging on empathy: Perspectives on Baltimore City's specialized prostitution diversion program. Women and Criminal Justice. 2012; 22(2):156-173. doi: 10.1080/08974454.2012.662131.

Singer, M. Specialized ethnographic methods: A mixed methods approach. AltaMira Press; Plymouth, UK: 2013. Studying Hidden and Hart-to Reach Populations.

Surratt HL, Inciardi JA. HIV risk, seropositivity and predictors of infection among homeless and nonhomeless women sex workers in Miami, Florida, USA. AIDS Care. 2004; 16(5):594-604. doi: 10.1080/09540120410001716397. [PubMed: 15223529]

Tiffany JS. Respondent-driven sampling in participatory research contexts: Participant-driven recruitment. Journal of Urban Health: Bulletin of the New York Academy of Medicine. 2006; 83(6 Suppl):i113-124. doi:10.1007/s11524-006-9107-9. [PubMed: 16933100]

Twill SE, Green DM, Traylor A. A descriptive study on sexually exploited children in residential treatment. Child and Youth Care Forum. 2010; 39(3):187-199. doi:10.1007/s10566-010-9098-2.

Urada LA, Simmons J. A collaborative methodology for investigating the ethical conduct of research on female sex workers in the Philippines. Journal of Empirical Research on Human Research Ethics. 2014; 9(1):41-45. doi:10.1525/jer.2014.9.1.41.

Van Leeuwen JM, Hopfer C, Hooks S, White R, Petersen J, Pirkopf J. A snapshot of substance abuse among homeless and runaway youth in Denver, Colorado. Journal of Community Health. 2004; 29(3):217-229. Retrieved from http://www.ncbi.nlm.nih.gov/pubmed/15141897. [PubMed: 15141897]

Voisin DR, Hong JS, King K. Ecological factors associated with sexual risk behaviors among detained adolescents: A systematic review. Children and Youth Services Review. 2012; 34(10):1983-1991. doi:10.1016/j.childyouth.2012.07.003.

Williamson C, Baker LM. Women in street-based prostitution: A typology of their work styles. Qualitative Social Work. 2009; 8(1):27-44. doi:10.1177/1473325008100420.

Williamson C, Folaron G. Understanding the experiences of street level prostitutes. Qualitative Social Work. 2003; 2(3):271-287. doi:10.1177/14733250030023004.

Wilson JM, Dalton E. Human trafficking in the heartland: Variation in law enforcement awareness and response. Journal of Contemporary Criminal Justice. 2008; 24(3):296-313. doi: $10.1177 / 1043986208318227$.

Zimmerman, C., Watts, C. WHO ethical and safety recommendations for interviewing trafficked women; Geneva WHO. 2003. p. 1-31.Retrieved from http://www.who.int/mip/2003/ other_documents/en/Ethical_Safety-GWH.pdf 